tary emeritus. By his tact and energy at the time of change of government at Rome, he was enabled to save the Archives of the Academy, of which during his lifetime he was one of the most active members.

Volpicelli was well known abroad, and the Emperor of Brazil when in Rome spent some time with the professor, and conferred upon him the grade of officer of the Imperial Order of the Rose. Volpicelli travelled much, and in 1850 he made a long stay in England, where he made the acquaintance of Faraday, Brewster, Airy, Murchison, Sabine, Panizzi, Wheatstone, and others, with whom he afterwards continued to correspond. In France and Switzerland also, he was the friend of the most eminent men of science.

Volpicelli was an energetic worker in his favourite field of electrical research, and to the last maintained with vigour the theory of Melloni, at which he had worked for twenty years. The papers and other works published by Volpicelli were very numerous; no less than 270 are enumerated in a list published by the Academy dei Lincei. Although he is chiefly known by his researches in electricity, these papers show that he did much other work in various departments of mathematics and physics. Volpicelli's papers will be found mainly in the Atti de l'Accademia dei Lincei, and the Comptes Rendus of the Paris Academy. Very few of them have, however, been translated into English, a circumstance which must be regretted for the sake of English scientific men, to many of whom Volpicelli's researches are known only by name. He died calmly on April 14, having been visited shortly before his death by the Pope's brother, Cardinal Pecci.

\section{AN AMERICAN SUGGESTION}

$\mathrm{W}^{\mathrm{E}}$ have occasionally noted in these columns the formation of mathematical societies, and we have ventured, in our ignorance, to suggest that as a consequence of the great advance in the cultivation of mathematics recently made by our American cousins, the time had come for the formation of an American or (following the analogy of associations nearer home) of a Baltimore Mathematical Society.

A short account of the Proceedings at the fifth meeting of the Lehigh Mathematical Society-recorded in the Bethlehem Daily Times (Pa.) for March 17 -may interest kindred societies on this side the Atlantic, and serve to show that the transactions of such learned bodies may contain "something of importance and profitable (sic) to the general reader."

It appears that in order to remedy the defects in the art of surveying, it has been made imperative (so says Mr. S. R. Vay, Civil Engineer, the reader of the paper ${ }^{1}$ ) by the American legislature that "each county should at its own expense and on its own land, plant, or erect, two monuments of stone, so that the straight line between them should be an exact and due meridian, or north and south line ; in order that thereby surveyors, by setting a compass on the one monument, and pointing it to the other, might readily ascertain the deviation or variation of the magnetic needle, and thus be prevented from committing errors in the determination of property lines and landmarks." His soul was much stirred at the ne rlect of this "scientific duty." It seemed to him that "the scientists of the valley ought to urge, with no uncertain voice, the erection of such or similar monuments. With but little extra expense they could easily be made to interest and to educate, as well as to serve the purpose designed by the legislature. Imagine, for instance, two beautiful granite monuments standing in appropriate

I Touching first upon the necessity of preserving boundaries and upon the methods employed by the ancients; tracing the word geometry to its source, and relating how the Egyptians were puzzled to find their landmarks, he then passed on to the discovery of the magnetic needle, and the perplexity caused to country surveyors by the deflection of the same. situations on the spacious ground of Lehigh University, one mounted with a sun-dial, and the other with an anemometer. On one of them should be cut in plain letters the latitude, longitude, and elevation above the sea of that exact spot, On the other should be recorded a statement of the mean annual temperature and rainfall of the valley. The axis of the sun-dial would not only point to the steadfast pole, but be parallel to the earth's axis ; it could, indeed, be furnished with a hoop or circle, to represent the equator, and with others to represent the meridians of Greenwich, Washington, and Bethlehem; a circle to indicate the ecliptic would not be difficult to add, which, by properly constructed clock-work should be always kept parallel to the real ecliptic itself. Thus all who might pass that way would be interested in reading the inscriptions and observing the time, and many would be instructed in the science of astronomy. Even to students it would be of benefit in lightening their mental struggles to grasp, conceive, and understand the idea of the ecliptic circle and the ecliptic plane."

In the discussion which followed, the President doubted the wisdom of the legislature, and thought the better way would be to require higher qualifications from surveyors.

Dr. H. E. Licks inquired the expense of such a sun-dial as Mr. Vay had described.

Mr. A. S. Tronomy said " it was usual to consider the ecliptic as a fixed plane when illustrating the yearly motion of the earth. When considering the daily rotation, however, be could see that Mr. Vay's plan had some advantage."

The next paper was by Prof. Ternion, "On the consequences which would result from denying or reversing the tenth axiom of Euclid." The argument, we learn, was "elaborate and profound, being exemplified by long formulas written on the blackboard." He showed that "if the properties of matter or space were such that the axiom became false, a knot could not be tied in a string, that a hollow rubber ball could be turned inside out without tearing or stretching, and that no satisfactory system of paper or silver money could be employed."

Mr. K. M. Puter considered the paper as an example of mathematical analysis, one of very great value, but he considered it fortunate that we cannot practically reverse the axioms of geometry. "If we could, the results would be disastrous." Our notice of the Proceedings at this interesting meeting have extended to some length, but they may be suggestive of matter for societies on this side of the world. We cannot close, without alluding to another feature, and that is the subsequent proceedings (unscientific) before the members separated.

Crackers and cheese were brought forward and the knot untied by the Secretary "without denying any axiom whatever." "The mathematical joke and the hearty laugh were heard," and, tell it not in Gath, they sang a song. Of a Mathematical Society not a hundred miles off, the first President wrote, "not a drop of liquor is seen at our meetings, except a decanter of water; all our heavy is a fermentation of symbols; and we do not draw it mild. There is no penny fine for reticence or occult science ; and as to a song! not the ghost of a chance."

\section{THE STANDING STONES OF CALLANISH}

THE object of the present paper is to describe the standing stones of Callanish, Island of Lewis, accompanied by notes of such measurements as the author was able to take during a somewhat hurried visit to these very interesting memorials of the early inhabitants of our islands.

Leaving the town of Stornoway, we soon find ourselves amongst great tracts of moorland, with sheets of water large and small on all sides. The deep black peat is being cut and piled up in to stacks, when, after being dried, it will serve for the winter's fuel. The peats in the Lewis 